\title{
Tussles and Rollovers: Negotiating Sickness Certification in Primary Care
}

\author{
Paula Byrne, Adele Ring, Peter Salmon, Chris Dowrick, Mark Gabbay \\ Institute of Psychology Health and Society, University of Liverpool United Kingdom, Liverpool, UK \\ Email: $\underline{\text { mbg@liv.ac.uk }}$
}

Received 1 October 2014; revised 29 October 2014; accepted 16 November 2014

Copyright $\odot 2014$ by authors and Scientific Research Publishing Inc.

This work is licensed under the Creative Commons Attribution International License (CC BY). http://creativecommons.org/licenses/by/4.0/

(c) (7) Open Access

\section{Abstract}

Sickness certification in primary care is increasingly the focus of new policies, practices and politics which are associated with keeping people in work rather than moving on to sickness absence. However, there are considerable tensions for practitioners from their role in sickness certification. The decision to issue a sicknote is influenced by a number of factors including the needs of their patient, their own attitudes towards work, and their responsibility to the state or employer. Some patients, such as those with Medically Unexplained Symptoms (MUS), are particularly challenging for Practitioners, as they do not fit the "sick role" and are difficult to negotiate with. We present the first taxonomy from actual sicknote consultations between General Medical Practitioners (GPs) and their patients, classifying the types of requests and the associated responses. Although, most sicknote requests do result in a sicknote, GPs do gather information about the patient's social, occupational, and family circumstances, negotiate absences from work, impose terms and conditions upon the patient, and challenge patients' illness constructions. Our findings suggest that, despite the tensions for GPs in managing these patients, sicknote consultations can be an important juncture for the clinicians and patients, particularly in light of the move from an illness deficit model towards a health capacity model, where work is considered health-giving, and not a barrier to illness recovery. This resonates with the switch in the UK to a "fitnote" approach from the previous "sicknote" one.

\section{Keywords}

Sickness Certification, Absenteeism, Consultations, Taxonomy, General Practitioner, Primary Care, Medically Unexplained Symptoms

\section{Introduction}

The relationships between work, health and related sickness certification are increasingly subjects for worldwide

How to cite this paper: Byrne, P., Ring, A., Salmon, P., Dowrick, C., \& Gabbay, M. (2014). Tussles and Rollovers: Negotiating Sickness Certification in Primary Care. Advances in Applied Sociology, 4, 247-260. 
political and policy debate and review (Gabbay, 2010 a \& b). The recent global recession will increase unemployment and competition for jobs, and decrease options for those with interrupted work through disability and illness. One political and cultural solution to increasing unemployment is to reduce the barriers to classifying those excluded from the jobs market as sick or disabled and hence unfit for work. In the past such individuals have been compensated with slightly higher welfare payments and benefits. Research indicates that only around $10 \%$ of those absent from work through illness for more than a year ever return to paid employment (DWP, 2005). Such claimants and their families are potentially locked into long-term relative deprivation with associated social exclusion and worse health than their employed peers (Waddell et al., 2003).

In the UK, attempts to avoid such trajectories have been reflected in a change in government policy with the publication of "Working for a Healthier Tomorrow" (Black, 2008), which marks a shift away from an illness deficit model towards a health capacity model within sickness certification discussions, and has been embedded within UK Government policy (http://programmeforgovernment.hmg.gov.uk/jobs-and-welfare/ 16 June 2010). Current evidence, which has been incorporated into policy, proposes that work has a positive impact on health (Ford et al., 2000; Wessley, 2004; Waddell \& Burton, 2006), with the concomitant caveat that loss of employment worsens health (Head et al., 2008). In the UK in April 2010, sickness certification switched from the sicknote certifying a period of no work capacity, to the "Fitnote", which focuses on work capacity and fitness for some work, as well as not fit for any work (Gabbay, 2010 a \& b; Shiels, Gabbay, \& Hillage, 2014).

There are a variety of sickness certification systems within Western Europe and the USA, with many countries having a similar system to the UK, whereby a relatively short self-certification period is followed by longer term certification usually by Primary Care or Welfare Payment System employed physicians (Wahlstrom \& Alexandersson, 2004). In the UK, General Practitioners (GPs) have historically been the gatekeepers to long term sickness absence and associated benefits through the inscription of a medical diagnosis upon a sickness certificate. However, there are tensions within the provision of sickness certification, as GPs often have to balance patient needs, their own obligations to the state, and their beliefs about work, health and benefits (Hiscock et al., 2009).

Talcott Parsons (1951a, 1951b), in his seminal work on the sick role, recognized that the experience of being ill is much more than a biological phenomenon. According to Parsons, there are social and cultural expectations around being ill: the individual has to seek medical help; and if validated, the sick individual is allowed temporary exemption from certain social duties and responsibilities, such as work; and only medical clinicians have the power and authority to give legitimacy to the patient's experience of illness. The doctor-patient relationship, according to Parsons (1951), which the patient is obliged to enter, is characterized by asymmetry: of medical knowledge, competence, authority, and power. By relinquishing the independence of health, and through seeking medical help, the individual is also accepting that illness is undesirable and will actively want to get well and become healthy again.

Parsons' concept of the sick role has been critiqued for a number of reasons, including the exclusion of chronic illnesses (Radley, 1994) which dominate current health horizons. More generally, the sick role was conceptualized in the 1950's when the protestant work ethic was prevalent and it was relatively rare for significant numbers of people to be unemployed or off work for a long time through sickness. During the past six decades, the work place and the conditions of employment have altered dramatically. Our conceptualization of sickness has changed as well, fuelled by new diagnostic categories and the negotiations of existing categories by interested organizations (Berg \& Timmermans, 2000; Hacking, 1999) along with contested categories such as depression (Dowrick, 2009). The acceptance of different types of illness, such as stress, and related absences from paid work has also reformulated the sick role, perhaps also evidenced by changes in the diagnostic categories written on sickness certificates, where "minor mental health problems" have overtaken "musculoskeletal" as the most used category in the UK (Shiels et al., 2004; CIPD, 2009).

An additional development of the sick role is the recognition that there are different types of patients who present within the health services; they are not a homogenous group. Some require immediate short-lived care, such as during pregnancy, others will need consistent long term care, with chronic conditions like diabetes or cardiovascular disease. Others will dip in and out of biomedicine, along with the use of alternative treatments or remedies. All will require different types of care and respond to medical expertise in a variety of ways. One group that has attracted attention is those with medically unexplained symptoms (MUS). Defining MUS is contested and has its own historical and political contingencies. The term MUS is a relatively recent phenomenon which can be traced back to the early 1980s (de Figueiro et al., 1980). However, its use in the medical literature 
is now widespread (Watkins, 2002). Within medicine, MUS are considered to be the manifestation of symptoms that have no pathological basis. Presentations of MUS are considered to be common (between 15\% and 30\%), in primary care (Kermayer \& Robbins, 1991; Peveler et al., 1997; Fink et al., 1999, Ring et al., 2005) and other medical specialties (Nimnuan et al., 2001).

Complex dynamics around negotiating outcomes are often played out in consultations, especially when diagnosis is difficult to determine or contested as in the case of individuals with MUS, where the management of symptoms can present a dilemma for GPs (Salmon et al., 2009). Herein lies the conundrum of sickness certification, specifically with MUS patients. Clinicians are trying to deal with several roles at one time: acting as a gatekeeper to state benefits which can allow an individual to retreat from paid employment; perform diagnostic work which can accurately reflect the presented symptoms; and crucially, make diagnostic decisions in light of patient's needs. Since MUS patients do not easily fit into the biological categories of disease, their somatic presentation is difficult for clinicians to effectively deal with (Peters et al., 1998; Salmon, 2000).

The current research literature around GP decision-making in sickness certification consultations suggest that the key risk factors for developing longer-tem absence are diagnostic category, age, sex and deprivation but these still only explain less than 30\% of the observed variance (Shiels \& Gabbay, 2007). Elsewhere, Hiscock and Ritchie (2001) suggest three types of GPs: those who want no role in sickness certification; those who do want to be involved; and those who want other agencies to be more closely involved. Hussey et al. (2004) propose several influences upon sickness certification including: GPs' strategies for implementation; the doctor/patient relationship; and who is in control within the consultation. They suggest that GPs use both flexible and fixed strategies about sickness certification, where the former includes acquiescence, and the latter includes negotiation with, and challenges to, the patient, which obviously take more time to play out within a consultation. Other research suggests that GPs who acquiesce to patients' requests for sick notes without discussion about work and other related issues are engendering poor doctor-patient relationships (O’Brien et al., 2008). Additionally, there is sickness certification research which reports on observed variations within and between countries, with factors shown to impact on certification including clinician behaviours; types of clinicians and where they work; definitions of functional capability and decision-making about somatic and non-somatic complaints; and for claimants: their diagnosis; socioeconomic conditions, and employment status (Wahlstrom \& Alexandersson, 2004; Arreloev et al., 2007; Swartling et al., 2008; Norrmen et al., 2008; Van Knorring et al., 2008).

However, to date, there is no reported research about interactions between GPs and patients during consultations about sickness certification. Thus, the aim of this paper is to present models of consultations between primary care clinicians and MUS patients about sickness certification from actual consultations. Our objectives were to test how GPs report they behave in published research against actual transcripts of relevant consultations; and to develop an initial taxonomy to inform a classification framework for future consultation analysis in prospective studies of work and health related research.

\section{Methods}

Forty two GPs (22 males, 20 females), out of 50 approached, with 5 - 42 years of medical experience from 11 primary care practices in the North West of England took part in the MUS research. Practice size ranged from 1 to 10 GPs (mean 4.5) and 2087 - 13,116 patients (mean 7564). Six practices were urban, four were suburban and one was rural.

Consecutive patients attending participating doctors on study days from January 2000 to March 2002 were approached by a researcher before consultation and asked for written consent to audio-record their consultation. Of 5083 patients 3136 consented. The eventual number of MUS patients (according to GP's completion of the checklist) was 420 patients. The criteria for designating patients as having MUS was based upon GPs completing a checklist immediately after each consultation to indicate whether there was: the presentation of a physical symptom; that could not be entirely explained by a recognisable physical disease. (A more detailed discussion of these issues can be found in Ring et al., 2005).

We analysed 65 of the 420 consultation transcripts from this project on MUS for this pilot taxonomy development. These transcripts had been identified as consultations in which the patient or GP refer to sickness certification using the relevant code from the Liverpool Clinical Interaction Analysis Scheme (LCIAS) (Ring et al., 2005; Dowrick et al., 2004; Salmon et al., 2005; Salmon et al., 2009). 


\subsection{Procedure}

Audio recordings of consultations meeting the research criteria were identified and anonymously transcribed.

\subsection{Analysis}

The transcripts were input into Atlas Ti (software for qualitative analysis). The data were thematically analysed (Miles \& Huberman, 1984; Patton, 1990) based on grounded theory (Glaser \& Strauss, 1967) by two of the authors (PB and MG). The process of data analysis took several stages: transcripts were coded and organised into categories and themes. The preliminary categories were: patient initiated request for sicknote, GP response, GP offer of sicknote, patient response. Emergent themes were: types of patient requests, subsequent GP responses, timing of requests, and GP offers of sicknotes. The development of the taxonomy model (Figure 1 and Figure 2) was iterative, using coded transcripts to test its validity.

\section{Results}

Table 1 summarises who initiated sicknote discussions (80\% were patient initiated) and the outcome in respect of certification.

\subsection{Patient and GP Strategies}

We present themes from our analysis representing the main strategies employed by patients and GPs when discussing sickness absence and related certification. To increase the utility of our findings we have categorised the consultations between patient-led; and GP-led discussions about sick notes, which provoke particular responses and are outlined in Figure 1 and Figure 2 and discussed below. Most of the sicknote consultation segments we studied were patient-led.

Patient Led Requests A) Direct Request

B) Immediate Action Required
GP Responses

Acknowledgement

Acquiescence

Fact-Finding: Occupation

Challenging the Patient

Link Work and Health Benefits

Avoid Illness Trajectory

Information Gathering

Negotiate Sickness Absence

Terms and Conditions Implied

C) Listing of Needs and "By the Way I Need a Sicknote"

Allow Time and Space

Compartmentalise Problems

D) Compliance with Previous terms and Conditions

Recognition and further Negotiation

E) "Out of the Blue" Requests

Acquiescence

Figure 1. Taxonomy of patient sicknote requests and GP responses.

Patient Presentations

A) Dramatic Narrative

B) Symptoms, Work and Health Presentations

C) GP-Led Renewal
Managing Sickness Absence

Moving Swiftly on

Patient Responses

Crisis management

Acceptance Refuse Offer

Figure 2. Taxonomy of GP-led offers. 
Table 1. Numbers of patient sicknote requests, GP sicknote offers, and refusals.

\begin{tabular}{cccc}
\hline & Patient Requests & GP Initiated Offers & Total \\
\hline Sicknotes Given & 46 & 10 & 56 \\
Sicknotes Not Given/Refused & 6 & 3 & 9 \\
& 52 & 13 & 65 \\
\hline
\end{tabular}

\subsection{Patient-Led Requests for Sicknotes}

Patient-initiated sicknote requests occurred at a variety of stages within the consultation (see Figure 1) and were also presented in a variety of ways. Direct requests, usually at the opening phase of a consultation was the commonest category $(n=28,54 \%)$. This was often linked to an urgent component-a note required immediately or already overdue, to emphasise the need for action. Second was the "listing of needs" and "by the way I need a sicknote" ( $n=14,27 \%)$, where the request occurred in the middle or end of the consultation. Two other categories were noted: "patient compliance with terms and conditions" ( $n=8,15 \%)$, again often found near the beginning; and the "out of the blue" request $(n=2,4 \%)$ in the middle of the consultation. For each of the patient requests, varieties of GP responses were found and are represented below.

\subsubsection{Direct Request}

These usually occurred in the opening exchanges as illustrated below.

Dr: Come in. Hello.

Pt: Hello Dr (name). Erm what I really came for is well you know I'm still off work?

Dr: Yes.

Pt: Erm so I need a note for work.

Dr: Right. (ID29)

We noted six different GP responses to these direct requests:

Acknowledgement. Often the GP acknowledged such requests but did not immediately provide the sicknote. Instead they waited until the patient had offered more information, or they themselves had offered more contextual detail to their decision to give a sicknote, as below.

Dr: I think I said at the time they always are quite slow.

Pt: Takes a long time.

Dr: Yeh it's like any other bone, it's got to mend.

Pt: Yeh. I think when you're in a heavy job as well cos you're not restin' it up.

Dr: Would some time off work be helpful for you?

Pt: Erm.

Dr: And have done with it [with all the] pressure.

Pt: [Get it out the way], yeh.

Dr: Yes, would that be helpful?

Pt: Yeh. (ID20)

Acquiescence. Another response to a direct request was for GPs to immediately consent without any indication that the patient would be challenged or asked for further information.

Pt: But I've come in as well, you gave me you know a sick note for er

Dr: No problem.

Pt: So I wondered if you'd renew it cos I'm still waiting.

Dr: Yeh no problem. (ID37)

Fact finding-Occupation. In response to direct sicknote requests, GPs often asked questions around the patient's job as a way of gathering information and possibly probing to find if there are any work related issues that will have a bearing on the patient's outcome. GPs questions about the patient's occupation can sometimes give clues about the patient's symptoms. 
Pt: What is my job?

Dr: $M m$.

Pt: I'm a chef, by occupation but, I do silver service waitering for them as well.

Dr: What's your job, what are you doing?

Pt: I work in a restaurant.

Dr: Right. OK and so what made you come in today? Was it the vomiting? (ID74)

Challenging the Patient. Sometimes GPs contested patients' accounts of their symptoms and illness labels:

Dr: I mean it wasn't actually a heart attack was it?

Pt: Suspected.

Dr: I think, they didn't confirm it. I think it was according to this letter, erm yeh, it wasn't a heart attack. It was just a nasty angina attack or something. [Right]. (ID27)

Linking Work with Improved Psychological Well-Being. At times GPs were keen to link reducing patient's anxiety with the continuation of work

Dr: A lot of people who suffer from anxiety find that they are worse when they're off work and at home cos they're sort of sitting thinking more [...] I think the sooner you manage to get back into work the better you'll find it, the easier to control the anxiety. [...] Because you'll have your routine back. (ID28)

Avoiding the Illness Trajectory. Some GPs sometimes directed discussions away from symptoms which may act as a barrier to work or day-to-day activities. In the example below, the patient had recently been in a car accident which had left them with some form of whiplash injury and residual anxiety. The GP articulates an implicit assumption that: work is considered to be a worthwhile activity; and s/he considers this patient to be "at risk" from dwelling on her/his car crash experience and allowing this psychological trauma to become a rationale for not returning to work.

Dr: It might be good actually to sort of carry on you know, with life as it were. Cos you know it puts everything back then doesn't it? (ID50)

Occasionally, GPs attempted to use humour to defuse a patient’s symptom presentation,

Pt: Erm so I need a note for work.

Dr: Right.

Pt: But also I've been having er problems with my eyes and my hands, erm you know when I press there the pain goes right up me arm.

Dr: What do you press there for?

Pt: Just to see if it's still hurting I think. It's like it was sore, and if I press, it's like the pain goes up me arm.

Dr: Cos I think you're pressing.

Pt: The two of them.

Dr: you're pressing on a nerve when you're pressing there.

Pt: Do you?

Dr: That's why the pain's shooting up your arm.

Pt: Oh right.

Dr: Just leave it alone. [Ha ha]. (ID29)

\subsubsection{Immediate Action Required}

Another relatively common pattern was when patients present the GP with an apparently non-negotiable request as illustrated below. Such strategies can be difficult to deal with as the request is presented as urgent and at times the additional complication of the patient's implied passive role in communicating a government agency or employer requirement. We noted that different responses by GPs at different points in the consultation could be found, as illustrated from one consultation, presented below.

Pt: Er I would like to know if I could have a sick note off you "cos I've got to go to the dole today". (ID19)

Information Gathering. Rather than immediately acquiescing to the patient demands, the GP requests information, such as inquiring about hospital tests which the patient had undergone, or the current status of symp- 
toms.

Dr: Have you heard from the hospital yet?

Pt: I went on Monday.

Dr: Oh you went right.

Pt: I felt dead sick on the Friday, I went on the Monday.

Dr: Yes.

Pt: And he said "ten days". I haven't heard nothing off the doctors, no, yet but

Dr: Mm. [...]

Dr: But I mean you should hope hear from the hospital soon anyway, in the next week or two I would imagine. So you need a sick note.

Pt: Cos I can't work or anything can I?

Dr: No, no (ID19)

Negotiate Sickness Absence. Only when the GP has enough understanding of the patient's situation is there an offer of a sicknote.

Dr: Should have them back by hopefully then. Should we put four weeks on this and see how you go?

Pt: Yes. OK that's it.

Dr: And something for your piles? (ID19)

As shown above, the GP firmly negotiates the amount of time which the patient can be off sick and deals with physical problems as well.

Terms and Conditions (Implied). In the example below, the patient had requested an emergency appointment and the GP asks the patient for their exact expectations of the consultation. In response to the patient's reply, the GP presents a short term strategy-mild sleeping medication, with the long term promise of a more in-depth consultation to discuss the patient's underlying issues and implies a longer term negotiation of the patient's symptoms in exchange for the patient's return for review soon.

Dr: Why don't we use something to try and get you some sleep for the next couple of days?

Pt: OK.

Dr: Just for a short period of time.

Pt: $O K$.

Dr'll give you some very mild tablets to take before you go to bed.

Pt: $O K$.

Dr: OK and let's do that for the next sort of over the weekend and see if you can get some rest, OK.

Pt: O.K that's fine, [that's fine].

Dr: And then I'd like to see you again [in a week's time] to sort of check everything else out and make sure there's no other reason why you're feeling like this, OK? [...]

Pt: Is it possible that that you could write something to my workplace?

Dr: What sort of thing are you thinking of?

Pt: Just say I'm having trouble sleeping, I'm you know a bit stressed, a bit depressed that's all [...]

Dr: So what I've put is that "you're suffering with insomnia, I've given you some treatment for this and I'll

see you again in a week's time”. (ID74)

\subsubsection{Listing of Needs and "By the Way, I Need a Sicknote"}

Patients within this study often presented many issues and symptoms which had to be dealt with in a particular consultation. However, one of the strategies used by patients was to "slip" in a request for a sicknote along with physical symptoms.

Pt: Erm I've got irritable bowel.

Dr: Right.

Pt: And it's caused through stress and erm I came, I joined here cos I moved address.

Dr: Right.

Pt: And I need a doctor's note and also I wanted to discuss the medication I'm on as well.

Dr: Right. (ID72) 
We noted two GP responses to such requests:

Allow Patient Time and Space. Often, GPs allowed the patient to present their symptoms or issues before making any attempts to deal with them. These long patient dialogues are often merely interspersed with brief acknowledgements and encouraging prompts, such as "mmm", and "I see". Explanatory models of symptoms and how they are interrelated to other issues are often presented by GPs, such as a psychological explanation illustrated below:

Pt: But you know like going to the toilet, I do leak a lot but I mean that is, you know I'm not going to get that seen to because I'm too nervous like. I mean that's probably with having the four kids and one thing and another.

Dr: You know the water you mean?

Pt: Ha, ha, you can't go anywhere, you know, I am terrible for that but then that's I think probably with having the four kids but I mean I'm not going to get that seen to, it's awkward but.

Dr: Well you know think about that another time. Erm.

Pt: I mean I broke me teeth, I can't even get round to going to the dentist. I can't eat nothing, I've got to take my teeth out, ha, ha, when I eat, I broke them on holiday. But it is the tiredness; do you know what I mean?

Dr: I mean the other thing is the tiredness is sometimes a symptom of depression erm. (ID16)

Compartmentalise Problems. Once patients had been given the opportunity to communicate their specific complaints, a GP strategy was to prioritise, and then deal with each issue.

Dr: I think for whatever reason, and I thought this last time, I think there's an element of possibly, stress, anxiety, depression causing your symptoms. That's my feeling.

Pt: Mm.

Dr: Especially now the fact that you've seen the results of as being normal.

Pt: $M m$.

Dr: And if I'm right then we have to discuss what we want to do about it. What you want to do about it and what I can suggest that might help you. (ID31)

And in the prioritising, there is also reassurance.

Dr: Let's have a look. Blackouts. That was August it started.

Pt: That was it.

Dr: Right, he thought it,

Pt: That's right, yes.

Dr: Which showed that your heart rate was all normal.

Pt: Uh huh.

Dr: And all the blood tests were normal. And he thought that the dizziness might be related to anxiety-you know when you get panicky.

Pt: Possibly yes. (ID49)

\subsubsection{Patient Compliance with Previous Terms and Conditions}

Another form of patient request was to mollify it with an example of compliance with terms and conditions previously agreed with the GP.

Dr: Good morning. Hi have a seat. What can we do for you?

Pt: Right you gave me a note for a month last time. I had to go and see a counsellor. I said to you, you know I'd go and see.

Dr: That's right.

Pt: So I went to see her on Friday. That's the earliest appointment I could get with her you know and erm I was telling her about being so tired. That's my main, I know it's (coughs) I can't breathe can I? Erm well I know it's my nerves with me as well. (ID18)

Thus the patient immediately signifies that they have followed through with the appointment with a counsellor which was part of the negotiations around the GP issuing a sicknote. 
Recognition and Further Negotiation. In this, and comparable cases, the doctor responds by recognising that the patient has followed clinical advice and then moves on to negotiating with the patient.

\subsection{5. "Out of the Blue" Requests}

As with any conversation, especially when one actor wants to obtain something from another, timing is everything. Patient's requests for sick notes were sometimes interjected at surprising moments in the consultation discussion when the conversation is flowing in one direction and is then suddenly taken in another.

Pt: I always worked every night when the kids were little, couldn't go to work of a day so I worked of a night, come in about 10 o'clock, get the kids up, so I never really had a rest, cos I went back to work when the kids were only months old, all of them.

Dr: Yes So maybe it's just your body, you don't know do you?

Dr: All catching up with you.

Pt: I know and four kids doesn't sound like a lot but...

Dr: That's plenty ha ha. Erm.

Pt: Could I have a note as well?

Dr: You can, that's just what I was going to get for you. (ID25)

Acquiescence. This patient strategy may lead to the GP being taken by surprise and agreeing to give a sicknote at that point in the consultation. However, such acquiescence by the GP was not restricted to this particular request, as mentioned previously, it was found in "direct requests" as well.

\subsection{GP-Led Discussion about Sicknotes}

Analysis suggests that, although most sicknote requests originate from the patient, there were consultations $(\mathrm{n}=$ 13) where GPs initiated discussions about sicknotes. This approach occurred in complex consultations where symptom presentations, along with psychological and social needs, are intertwined. Within these consultations, there were 3 types: dramatic narratives $(n=5)$; symptoms, health and work presentations $(n=4)$; and renewal of sicknote $(n=4)$. We also present some of the patients' responses to these sicknote offers.

\subsubsection{Dramatic Narrative}

At times patients present particular traumatic incidents in emotionally charged language which adds to the patient's urgency of needs within the consultation.

Pt: Erm I've had a lot of problems erm went down to get a job in Anyplace. Err had a lot of problems since I've been there and I've had problems at work now as well. To the point where I became suicidally depressed. I've tried to take an overdose twice in the past few months. [...] it started with getting mugged soon after I went there and then attacked by the landlord, at the place where I was staying. [...] He threatened me basically cos he was losin money, he couldn't stand that. Erm then he had the police arrest me cos he claimed I'd damaged his flat and that went on for months about whether I was going to get prosecuted or not. I'm not just, it was just too much. When I've since had the manager tried to bully me at work and that was just the last straw. (ID33)

Crisis Management. GPs effectively deal with a number of issues at once with such presentations. For example, if we follow on from the consultation illustrated above, the GP responds by giving the patient permission for a sicknote, and then moves on to the potential mental health agenda being played out in the patient's narrative, by querying their use of anti-depressants.

Dr: So first things first, we need to give you a note that you need to give to work in Anyplace so you can take some time off that's no problem at all. You last took Prozac when? September? (ID33)

\subsubsection{Symptoms, Work and Health Presentations}

In some consultations, where the GP offers the sicknote before the patient requests one, this follows discussions about the impact of health problems on work and or vice versa. This is generally embedded within discussions about symptoms and their illness(es) in general, as illustrated below.

Pt: Yeah. It's not like me to to not bother to go into work. 
Dr: No.

Pt: I think that's concerned me. I don't know whether to go into work next week. I'm just not.

Dr: I don't think you should, I don't think you should, not when you're feeling like this really. I think you'll end up err, I think you'd end up err making yourself more poorly. (ID65)

Managing Sickness Absence. By leading patients into discussions, where a clear relationship between work and illness is explored, the GP is then enabled to manage the sickness absence more actively. Specifically, GPs can control the length of sickness absence and then ensure the patient returns for another consultation. In the illustration below, the patient is channelled into a future consultation through the prescription of anti-depressants, a two week sicknote and a firm GP negotiating style.

Pt: ... I feel as if like there's a problem there that's blockin "me from goin" into work, do ya know what I mean?

Dr: Right well in that case let me give you a prescription and I'll do a note to cover you for that time, from when you came to see me for another fortnight.

Pt: Right.

Dr: And we'll meet up in a fortnight to see how you're doing.

Pt: Ok. (ID32)

Moving Swiftly on. Although small in number, the negotiation sequences suggest a tussle for dominance in the negotiations. For example, in some instances, where a long symptom discussion has preceded the GP offer of a sicknote, the patient responds to the offer by barely recognizing or acknowledging it and swiftly moves on by asking an unrelated question.

Dr: Do you need a note for work?

Pt: Yeah I think erm can I ask your opinion on steroids? (ID45)

Renewal of Sick Note. Another situation in which GPs offer a sicknote is when they realise that the current one is due for renewal, before the patient has asked for it. This can be accompanied by occupational discussions. In the example below, the sicknote is given with a clear time limit, but with the assurance that the patient can return for more sick leave if needed.

Pt: I've been taking Brufen.

GP: Fine, that's probably the best. You need a note really too.

Pt: Yes, basically just to err I don't know. It does feel like it's getting better, I was panicking at the

GP: If I give you a note for another week.

$P t: O K$

GP: See how you are, I mean obviously if you're not completely better by then come back and see us but er, I mean do you suffer with your back normally? (ID18)

Refusal of Sicknote Offer. Negotiations don't always lead to a sicknote. In earlier examples in this paper the GP declined the request; sometimes an offer of a sicknote was turned down by the patient. In the example below, despite the GP offering a sicknote three times, the patient decides to carry on working as the current episode of illness (labrynthitis) is perceived not to warrant time off work.

Dr: What about work? Do you need time off work with it?

Pt: Er no I don't think so cos it's not at it's worst at the moment (coughs). [...]

Dr: So you're happy to go into work cos I'm more than happy to do a note If you.

Pt: Mm. I mean if I decide when I get in there that I don't well.

Dr: Sure, well just let us know. (ID14)

\section{Discussion}

This is the first study to examine how sick note certification is negotiated in MUS consultations, using direct rather than recalled data. We found that most requests were patient initiated $(n=52,80 \%)$, and resulted in a sicknote. However, it was rare that GPs simply wrote out a sicknote. Instead our results show there is considerable negotiation being undertaken between GPs and patients, whether that is the patient presenting with accounts 
of compliance with previous terms and conditions, or the GP determining the amount of time allowed for sickness absence-ensuring that the patient either returns into primary care or returns to work.

Our research indicates that these consultations and the sick role are more complex and ambiguous than assumed in Parsons' (1951) original model. One of the central tenets of the model is that there is an asymmetry in the relationship, where the doctor is traditionally viewed as powerful and authoritative, and the patient will accept the doctor's treatment. Although GPs do act as gatekeepers to state benefits-only they can inscribe text on a "sicknote", patients with MUS manifest uncertainty in the relationship-diagnosis is by definition unclear. MUS patients don't "fit" into diagnostic labels, their multiple presentation of many symptoms can be a manifestation of psychological issues, life events that are difficult to deal with, a dependency upon medicine and its practitioners to "fix" their problems, and culturally, nowhere else for them to go.

These patients are difficult to accommodate within medicine as they have poor relationships with GPs. Their ymptoms and consequent needs are often beyond the remit of the standard primary care consultation, and the translation of patient's symptoms and illness to disease and a diagnostic category is challenging for clinicians with this group. Thus with MUS the Parsonian relationship starts to become diffuse and less distinct. But as reported elsewhere (Salmon, 2000), it is not necessarily the diagnosis that is important, it is the recognition of the symptoms as "genuine"-especially by health professionals, which is important for patients. However, within sickness certification the need for a diagnosis or some form of diagnostic label is required, which may influence the GP's response, but the trajectory is unknown. Whilst GPs might be wary of the veracity of the patient's complaint, they may also see the sicknote as part of the management, or a token to use, to influence compliance with other suggestions for care and health management. Our results suggest that writing a sicknote for MUS patients follows a negotiation pathway, and the sicknote request or offer may become a "negotiation pathway" token. Whilst this observation holds true in many of these complex consultations outwith the predicted Parsonian model, we speculate that this group of patients provide rich and varied data about sicknote certification which can then be applied to other patients. A comparable study of sickness absence negotiations in consultations with less uncertainty is necessary to test the wider applicability of our "negotiation pathway" taxonomy to understand the narratives to help GPs manage sickness certification more confidently. Additionally, sickness certification is generally viewed by GPs as onerous and a distraction from their main role-to diagnose and manage patientsmirroring the "frustrations" of managing MUS. Thus, our research is at a juncture within medicine which is particularly challenging for primary care physicians, but, nonetheless our findings are relevant and applicable to other patients and consultations.

Our data have limitations. They represent one consultation in what may have been a series of such meetings between the patient and health professionals. Additional observational data may have contributed to our results. For example, GPs may have the sicknote pad out on their desk whilst talking to the patient, which may tacitly imply that one will be given at the end of the consultation. In particular, where we noted GPs immediately acquiescing to patient sicknote requests, there may have been previous agreements between the GP and patient about the length of sickness absence. Such actions may have an effect upon subsequent discussions, patients may feel that they can discuss their issues more freely if they know that a sicknote has already been negotiated. Furthermore we remain unsure about the impact of other factors, such as what proportion of the patients were in paid work rather than unemployed, which may influence GP responses and patient requests, and whether the relatively active engagement of GPs in sicknote discussions is peculiar to MUS patients or reflects that this is commoner than previously assumed.

Our purpose is to use these consultations to describe patterns of sicknote discussions which can also be used by GPs to manage them in the context of changing legislation and shifting beliefs about sickness absence. For example, the UK shifted from sicknotes to "fitnotes" in 2010, which is predicted to shift the consultation dynamic. GPs are expected to take a more active role now the Fit Note has been introduced (Gabbay, 2010 a \& b). There is evidence that this policy shift to assessing work capacity rather than incapacity is reducing certified sickness absence periods, although less than anticipated use is being made of the partially fit for work option than had been hoped for (Shiels et al., 2013 \& 2014).

Two key points relevant to this new challenge can be drawn from our taxonomy. We are able to distinguish between patient and GP initiated sicknote discussions, and describe the consequent responses which demonstrated a complexity beyond the patient request-GP acquiescence anecdotal model. We also suggest strategies that actively negotiate sickness absence (planned absenteeism) or prevent presenteeism (where patients unfit for work "soldier on"). Although most of the requests resulted in a sicknote, GP's responses to patient requests were 
rarely to simply issue a sicknote, there were many techniques employed by GPs to gather more information about occupation, social networks, and current life burdens. Discussions about the importance of work, and indeed recuperation from injury, were presented as essential goals for patients to attain. GPs may be better prepared therefore to manage the additional complexity the Fit Note presents with the options of phased returns or role modification than had been assumed.

Our taxonomy of consultations demonstrate negotiating strategies which can be implemented by GPs when facilitating their emerging role, from providing sicknotes to discussing patients work ability, along with phased returns to work and progress reviews. In light of our findings, we consider that there is scope for training programmes around sicknote certification, within GP's professional development. Many GPs are highly skilled at the "standard" consultation, and insights gained here could be embedded within managing sicknote certification negotiations.

\section{Acknowledgements}

We acknowledge the cooperation of the patients, practice staff and GPs for their time and support for the original study upon which these data analyses are based.

\section{References}

Arrelov, B., Alexanderson, K., Hagberg, J., Lofgran, A., Nilsson, G., \& Ponzer, S. (2007). Dealing with Sickness Certification-A Survey of Problems and Strategies among General Practitioners and Orthopaedic Surgeons. BMC Public Health, 7, 273.

Berg, M., \& Timmermans, S. (2000). Orders and Their Others: On the Constitution of Universalities in Medical Work. Configurations, 8, 31-61. http://dx.doi.org/10.1353/con.2000.0001

Black, C. (2008). Working for a Healthier Tomorrow. London: TSO.

CIPD (2009). Annual Survey Report 2009: Absence Management. London: Chartered Institute of Personnel and Development.

de Figueiredo, J. M. et al. (1980). Briquest Syndrome in a Man with Chronic Intractable Pain. John Hopkins Medical Journal, 147, 102-106.

Department for Work and Pensions (2005). Chapter 4: Supporting People with Health Conditions and Disabilities. Five Year Strategy Opportunity and Security throughout Life Cm 6447, Norwich: HMSO. 44-51.

Dowrick, C. (2009). Beyond Depression: A New Approach to Understanding and Management (2nd ed.). London: Oxford University Press. http://dx.doi.org/10.1093/med/9780199545292.001.1

Dowrick, C., Ring, A., Humphris, G. M., \& Salmon, P. (2004). Normalisation of Unexplained Symptoms by General Practitioners: A Functional Typology. British Journal of General Practice, 54, 165-170.

Fink, P., Sorensen, L., Engberg, M., Holm, M., \& Munk-Jorgensen, P. (1999). Somatization in Primary Care: Prevalence, Health Care Utilization, and General Practitioner Recognition. Psychosomatics, 40, 330-338. http://dx.doi.org/10.1016/S0033-3182(99)71228-4

Ford, F., Ford, J., \& Dowrick, C. (2000). Welfare to Work: The Role of General Practice. British Journal General Practice, 50, 497-500.

Gabbay, M. (2010). Electronic Fit Notes: Sickness Certification in the New Decade. British Journal General Practice, 60, 235-236. http://dx.doi.org/10.3399/bjgp10X483841

Gabbay, M. B. (2010). Access to Welfare Benefits in Primary Care. British Medical Journal, 341, c3642. http://dx.doi.org/10.1136/bmj.c3642

Glaser, B. G., \& Strauss, A. L. (1967). The Discovery of Grounded Theory: Strategies for Qualitative Research. Chicago, IL: Aldine Publishing Company.

Hacking, I. (1999). The Social Construction of What? Cambridge, MA: Cambridge University Press.

Head, J., Ferrie, J. E., Alexandersson, K., Westerhund, H., Vahtera, J., \& Lirimaki, M. (2008). Diagnosis-Specific Sickness Absence as a Predictor of Mortality: The Whitehall II Prospective Cohort Study. British Medical Journal, 337, a1469. http://dx.doi.org/10.1136/bmj.a1469

Hiscock, J., \& Ritchie, J. (2001). The Role of GPs in Sickness Certification. Research Report No 148. DWP: TSO.

Hiscock, J., Byrne, P., Peters, S., Westlake, D., \& Gabbay, M. (2009). Complexity in Simple Tasks: A Qualitative Analysis of GPs' Completion of Long Term Incapacity Forms. Primary Health Care Research and Development, 10, $254-269$.

http://dx.doi.org/10.1017/S1463423609001236 
Hussey, S., Hoddinott, P., Wilson, P., Dowell, J., \& Barbour, R. (2004). Sickness Certification System in the United Kingdom: Qualitative Study of Views of General Practitioners in Scotland. British Medical Journal, 328, 88-93. http://dx.doi.org/10.1136/bmj.37949.656389.EE

Kermayer, L. J., \& Robbins, J. M. (1991). Three Forms of Somatization in Primary Care: Prevalence, Co-Occurrence and Sociodemographic Characteristics. Journal Nervous Mental Disorders, 179, 647-655. http://dx.doi.org/10.1097/00005053-199111000-00001

Miles, M. B., \& Huberman, A. M. (1984). Qualitative Data Analysis. Newbury Park, CA: Sage.

Nimnuan, C., Hotopf, M., \& Wessely, S. (2001). Medically Unexplained Symptoms. An Epidemiological Study in Seven Specialities. Journal Psychosomatic Research, 51, 361-367. http://dx.doi.org/10.1016/S0022-3999(01)00223-9

Norrmen, G., Svardsudd, K., \& Andersson, D. K. G. (2008). How Primary Health Care Physicians Make Sick Listing Decisions: The Impact of Medical Factors and Functioning. BMC Family Practice, 9, 3. http://dx.doi.org/10.1186/1471-2296-9-3

O’Brien, K., Cadbury, N., Rollnick, S., \& Wood, F. (2008). Sickness Certification in the General Practice Consultation: The Patients’ Perspective, a Qualitative Study. Family Practice, 25, 20-26. http://dx.doi.org/10.1093/fampra/cmm076

Parsons, T. (1951a). The Social System. Chicago, IL: Free Press.

Parsons, T. (1951b). Illness and the Role of the Physician: A Sociological Perspective. Journal of Orthopsychiatry, 21, 452460. http://dx.doi.org/10.1111/j.1939-0025.1951.tb00003.x

Patton, M. Q. (1990). Qualitative Evaluation and Research (2nd ed.). Newbury Park, CA: Sage.

Peters, S., Stanley, I., Rose, M., \& Salmon, P. (1998). Patients with Unexplained Symptoms: Sources of Patients’ Authority and Implications for Demands on Medical Care. Social Science and Medicine, 46, 559-565. http://dx.doi.org/10.1016/S0277-9536(97)00200-1

Peveler, R., Kilkenny, L., \& Kinmonth, A. M. (1997). Medically Unexplained Physical Symptoms in Primary Care: A Comparison of Self-Report Questionnaires and Clinical Opinion. Journal Psychosomatic Research, 42, 253-260. http://dx.doi.org/10.1016/S0022-3999(96)00292-9

Radley, A. (1994). Making Sense of Illness: The Social Psychology of Health and Disease. London: Sage Publications

Ring, A., Dowrick, C., Humphris, G. M., Davies, J., \& Salmon, P. (2005). The Somatising Effect of Clinical Consultation: What Patients and Doctors Say and Do Not Say When Patients Present Medically Unexplained Physical Symptoms. Social Science and Medicine, 61, 1505-1515. http://dx.doi.org/10.1016/j.socscimed.2005.03.014

Salmon, P. (2000). Patients Who Present with Physical Symptoms in the Absence of Physical Pathology: A Challenge to Existing Models of Doctor-Patient Interaction. Patient Education Counselling, 39, 105-113. http://dx.doi.org/10.1016/S0738-3991(99)00095-6

Salmon, P., Ring, A., Dowrick, C., \& Humphris, G. (2005). What Do General Practice Patients Want When They Present Medically Unexplained Symptoms, and Why Do Their Doctors Feel Pressured? Journal of Psychosomatic Research, 59, 255-260. http://dx.doi.org/10.1016/j.jpsychores.2005.03.004

Salmon, P., Ring, A., Davies, J., Humphris, G., \& Dowrick, C. (2009). Primary Care Consultations about Medically Unexplained Symptoms: How Do Patients Indicate What They Want? Journal of General Internal Medicine, 24, 450-456.

Shiels, C., \& Gabbay, M. B. (2007). Patient, Clinician and General Practice Factors in Long-Term Certified Sickness. Scandinavian Journal of Public Health, 35, 250-256.

Shiels, C., Gabbay, M. B., \& Ford, F. M. (2004). Patient Factors Associated with Duration of Certified Sickness Absence and Transition to Long-Term Incapacity. British Journal of General Practice, 54, 86-91.

Shiels, C., Hillage, J., Pollard, A., \& Gabbay, M. (2013). Evaluation of the Statement of Fitness for Work (Fit Note): Quantitative Survey of Fit Notes. DWP Report 841, London: HMSO.

Shiels, C., Gabbay, M., \& Hillage, J. (2014). Factors Associated with Prevalence and Types of “May Be Fit” Advice on Fit Notes. British Journal of General Practice, 64, 131-132.

Swartling, M. S., Alexanderson, K. A. E., \& Wahlstrom, R. A. (2008). Barriers to Good Sickness Certification-An Interview Study with Swedish General Practitioners. Scandinavian Journal of Public Health, 36, 408-414. http://dx.doi.org/10.1177/1403494808090903

Van Knorring, M., Sundberg, L., Lofgren, A., \& Alexanderson, K. (2008). Problems in Sickness Certification of Patients: A Qualitative Study on the Views of 26 Physicians in Sweden. Scandinavian Journal of Primary Health Care, 26, 22-28. http://dx.doi.org/10.1080/02813430701747695

Waddell, G., \& Burton, A. K. (2006). Is Work Good for Your Health and Well-Being? London: TSO.

Waddell, G., Burton, A. K., \& Maine, C. J. (2003). Screening for Risk of Long-Term Incapacity: A Conceptual and Scientific Review. London: Royal Society of Medicine Press. 
Wahlstrom, R., \& Alexanderson, K. (2004). Physicians’ Sick-Listing Practices. Scandinavian Journal of Public Health, 32, 222-255.

Watkins, P. (2002). Medically Unexplained Symptoms. Clinical Medicine, 2, 389-390.

http://dx.doi.org/10.7861/clinmedicine.2-5-389

Wessley, S. (2004). Mental Health Issues. In K. Holland-Elliott (Ed.), What about the Workers? (pp. 41-46). London: Royal Society of Medicine Press Ltd. 
Scientific Research Publishing (SCIRP) is one of the largest Open Access journal publishers. It is currently publishing more than 200 open access, online, peer-reviewed journals covering a wide range of academic disciplines. SCIRP serves the worldwide academic communities and contributes to the progress and application of science with its publication.

Other selected journals from SCIRP are listed as below. Submit your manuscript to us via either submit@scirp.org or Online Submission Portal.
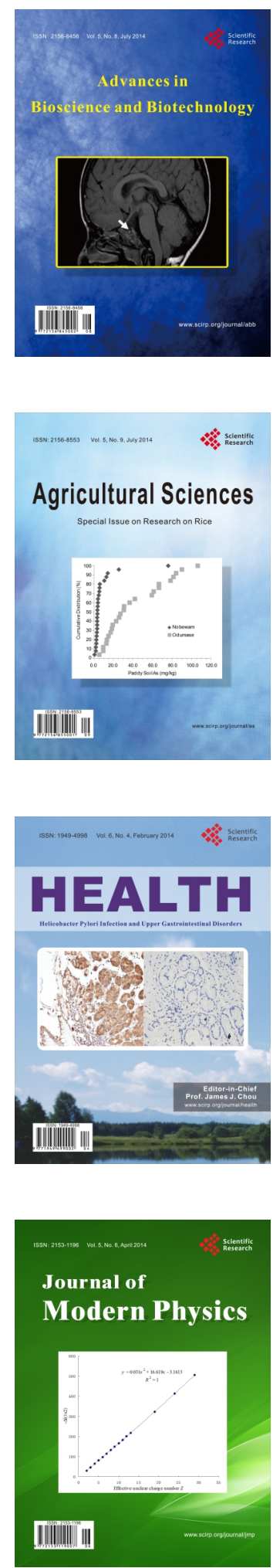
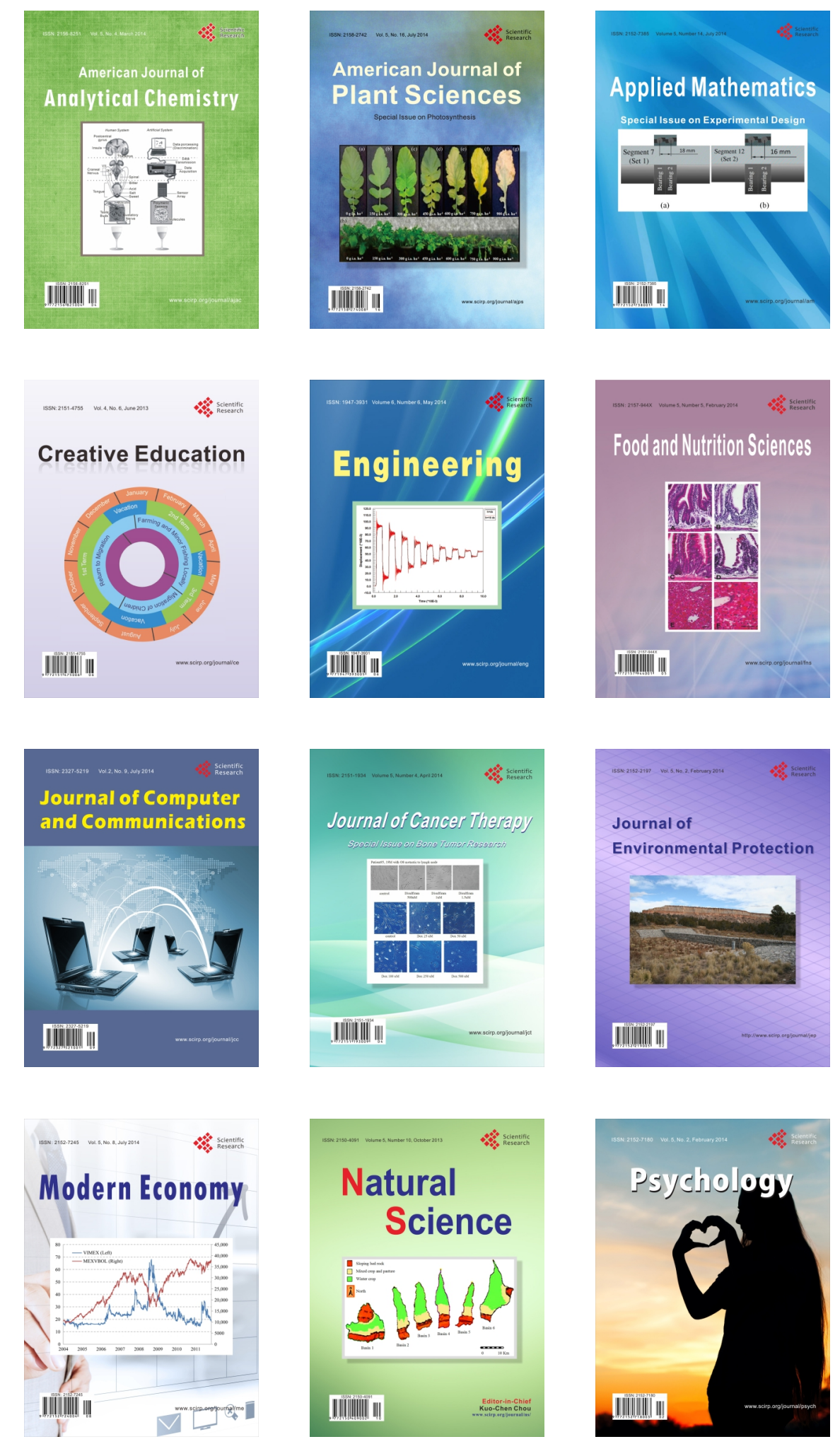